\title{
The Impact of Gastrointestinal Complications on Patients who Undergo Coronary Artery Bypass Grafting
}

Anthony Lemaire*, George Batsides, Aziz Ghaly, Al Solina, Victor Dombrovsky, Alan Spotnitz, and Leonard Y Lee

Rutgers-Robert Wood Johnson University Hospital, New Jersey, USA

\begin{abstract}
Objective: The incidence of gastrointestinal (GI) complications in patients undergoing coronary artery bypass grafting $(C A B G)$ is increasing as the population ages. The reported incidence ranges from $0.3 \%$ to $3.7 \%$. Coronary Artery Bypass Grafting (CABG) is one of the most common operations performed. The outcome of patients who undergo abdominal operations for Gl complications after CABG is not known. The purpose of the study is to determine the impact of abdominal surgery on patients who undergo CABG.
\end{abstract}

Methods: A retrospective review of nationwide data of all patients undergoing CABG from 2006 to 2010. A total of 160,513 patients who underwent CABG were reviewed.

Results: A total of 236 patients out of the 160,513 patients who underwent CABG developed GI complications that required abdominal surgery. The abdominal procedures included small and large bowel resections as well as colostomy formation. The indications for abdominal surgery varied and included ischemic bowel, and bowel obstruction. The patients who underwent concomitant abdominal surgery were more likely to develop renal Confidence Interval $(\mathrm{Cl})(8.5$ to 14.2$)(\mathrm{P}<0.0001)$, respiratory $\mathrm{Cl}(8.5$ to 14.8$)(\mathrm{P}<0.0001)$, and infectious $\mathrm{Cl}(16.3$ to 28.6) $(\mathrm{P}<0.0001)$ complications. They were also more likely to have higher mortality $\mathrm{Cl}(16.2$ to 29.0$),(\mathrm{P}<0.0001)$ Patients who underwent abdominal operations had longer length of stay (LOS) $37.23 \pm 32.8$ days versus $8.2 \pm 6.1$ days $(P<0.0001)$ and higher hospital charges, $\$ 389,586 \pm 260,546$ compared to $\$ 111,290 \pm 82,462.2(P<0.0001)$.

Conclusion: Although rare, the impact of abdominal surgery resulting from $\mathrm{Gl}$ complications is significant. The patients who had abdominal surgery and underwent CABG were more likely to develop multiple complications. As a result, these patients had a higher rate of mortality, longer LOS, and higher hospital costs. Taken together, these results indicate that patients with $\mathrm{Gl}$ complications should be identified promptly and aggressively treating these patients is of paramount importance.

\section{Keywords: CABG; Hypoperfusion; Complication}

\section{Introduction}

Gastrointestinal (GI) complications have been reported to occur after cardiac surgery $0.29 \%-5.5 \%$ and are associated with mortality rates of $11 \%-72 \%[1-4]$. The high mortality in these patients has been attributed to delayed diagnosis and treatment of GI complications. In addition, these patients frequently have serious associated medical problems and limited physiologic reserve. The major factor in precipitating GI complications after cardiac surgery is likely reduced cardiac flow with hypoperfusion of end organs [5]. Coronary Artery Bypass Grafting (CABG) is one of the most common operations performed. The outcome of patients who undergo abdominal operations for GI complications after CABG is not known. The purpose of the study is to determine the impact of abdominal surgery on patients who developed GI complications after CABG.

\section{Methods}

A retrospective review of nationwide data of all patients undergoing CABG from 2006 to 2010.

\section{Data source}

Nationwide Inpatient Sample (NIS) from the year 2002 to the year 2009 was used for this study. This is the largest all-payer database in the U.S. that is developed as part of the AHRQ (Agency for Healthcare Research and Quality) Healthcare Cost and Utilization Project (HCUP) and includes information about $20 \%$ of all hospitalizations in approximately 1,000 non-federal short-term hospitals. The most current NIS contains inpatient stay records from 45 states and comprises over 96 percent of the United States population. The sampling strategy of this database provides opportunity for computing nationwide estimates. Detailed NIS documentation with the description of all data elements is available at http://www.hcup-us.ahrq.gov/db/nation/nis/ nisdbdocumentation.jsp

\section{Statistical analysis}

Data analysis and all statistics were performed with SAS 9.2 software (SAS Institute, Cary, NC). Hospital mortality was defined as any-cause death during hospitalization and was calculated for each group as a number of patients who died divided by the total number of patients in this group and expressed as a percentage. To calculate hospital cost we used the HCUP Cost-to-Charge Ratio Files that allow conversion of hospital charges in the database to actual hospital reimbursement. Difference between two groups for categorical variables was tested with chi-square bivariate analysis. Controlling for the confounding effects was performed with the multivariable logistic regression analysis with

*Corresponding author: Anthony Lemaire, Assistant Professor, Division of Cardiothoracic Surgery, Department of Surgery, RUTGERS-Robert Wood Johnson University Hospital, 125 Paterson Street, New Brunswick, New Jersey, 08903, USA, Tel: 732-235-6171; Fax: 732-235-8727; E-mail: Lemairan@umdnj.edu

Received February 23, 2014; Accepted April 08, 2014; Published April 15, 2014

Citation: Lemaire A, Batsides G, Ghaly A, Solina A, Dombrovsky V, et al. (2014) The Impact of Gastrointestinal Complications on Patients who Undergo Coronary Artery Bypass Grafting. J Cardiovasc Dis Diagn 2: 153. doi:10.4172/2329-9517.1000153

Copyright: $\odot 2014$ Lemaire A, et al. This is an open-access article distributed under the terms of the Creative Commons Attribution License, which permits unrestricted use, distribution, and reproduction in any medium, provided the original author and source are credited. 
adjustment by age, gender, race, comorbidities, and other possible confounders. Because numeric variables hospital length of stay (LOS) and cost were not normally distributed and highly skewed to the right, we calculated their medians in various groups and compared intergroup differences with the non-parametric Wilcoxon rank sum test. A value of $\mathrm{P}<.05$ was considered as statistically significant. The study was approved by the Institutional Review Board of the University of Medicine and Dentistry of New Jersey - Robert Wood Johnson Medical School.

\section{Results}

A total of 160,513 patients who underwent CABG were reviewed (Table 1). A total of 236 patients out of the 160,513 patients $(0.15 \%)$ who underwent CABG developed GI complications that required abdominal surgery. The abdominal procedures included small and large bowel resections as well as colostomy formation. The indications for abdominal surgery varied and included ischemic bowel, and bowel obstruction. The patients who underwent concomitant abdominal surgery were more likely to develop renal CI (8.5 to 14.2) $(\mathrm{P}<0.0001)$, respiratory $\mathrm{CI}(8.5$ to 14.8$)(\mathrm{P}<0.0001)$, and infectious $\mathrm{CI}(16.3$ to 28.6$)$ $(\mathrm{P}<0.0001)$ complications. They were also more likely to have higher mortality CI $(16.2$ to 29.0$),(\mathrm{P}<0.0001)$. Patients who underwent abdominal operations had longer length of stay (LOS) $37.23 \pm 32.8$ days versus $8.2 \pm 6.1$ days $(\mathrm{P}<0.0001)$ and higher hospital charges, $\$ 389,586$ $\pm 260,546$ compared to $\$ 111,290 \pm 82,462.2(\mathrm{P}<0.0001)$.

\section{Discussion}

The data from our study shows that patients who undergo abdominal surgery after GI complications have a higher rate of morbidity and mortality. These patients were noted to have more renal, respiratory, and infectious complications. The patients with GI complications who had abdominal surgery also had a higher mortality. The incidence of GI complications after cardiac surgery is low, but the mortality and morbidity, as well as the cost in terms of prolonged hospitalization, are all considerable. Delayed recognition of these complications leads to a high incidence of morbidity and mortality, therefore prompt diagnosis and treatment are essential.

The prevention, early diagnosis and treatment of GI complications

\begin{tabular}{|c|c|c|c|}
\hline \multirow{2}{*}{ Characteristics } & \multicolumn{2}{|c|}{ CABG } & Total \\
\cline { 2 - 4 } & with AS & w/o AS & \\
\hline Age, years (mean \pm SD) & $70.3 \pm 9.1$ & $65.2 \pm 10.3$ & $65.2 \pm 10.3$ \\
\hline $40-59$ & & & \\
\hline $60-69$ & $30(12.7 \%)$ & $48,770(30.4 \%)$ & $48,800(30.4 \%)$ \\
\hline $70-79$ & $75(31.8 \%)$ & $54,568(34.1 \%)$ & $54,643(34.1 \%)$ \\
\hline $80+$ & $90(38.1 \%)$ & $43,466(27.1 \%)$ & $43,556(27.1 \%)$ \\
\hline Gender: & $41(17.4 \%)$ & $13,473(8.4 \%)$ & $13,514(8.4 \%)$ \\
\hline males & & & \\
\hline females & $182(77.1 \%)$ & $118,064(73.7 \%)$ & $118,246(73.7 \%)$ \\
\hline missing & $54(22.9 \%)$ & $42,205(26.3 \%)$ & $42,259(26.3 \%)$ \\
\hline Race: & 0 & 8 & 8 \\
\hline whites & & & \\
\hline blacks & $175(74.1 \%)$ & $110,469(68.9 \%)$ & $110,644(68.9 \%)$ \\
\hline Hispanics & $12(5.1 \%)$ & $8,603(5.4 \%)$ & $8,615(5.4 \%)$ \\
\hline other and missing & $11(4.7 \%)$ & $9,404(5.9 \%)$ & $9,415(5.9 \%)$ \\
\hline Total & $38(16.1 \%)$ & $31,801(19.8 \%)$ & $31,839(19.8 \%)$ \\
\hline
\end{tabular}

"CABG: Coronary Artery Bypass Graft; AS: Abdominal Surgery; SD: Standard Deviation

Table 1: Socio-demographic characteristics of the study population. after cardiac surgery must gain significance in order to improve the outcome of these patients. There are a few studies that have addressed this issue such as Yoshida et al., and Rodriguez et al. [6,7]. These authors also support the notion that GI complications after CABG although rare can be lethal. The occurrence of life-threatening GI complications after cardiopulmonary bypass (CPB) was first reported in 1963 [8]. The pathophysiology of GI complications following cardiac surgery has not been well elucidated. Low cardiac output resulting in visceral hypoperfusion and mucosal ischemia and necrosis has been suggested on by multiple authors [1,9]. Multiple risk factors have been considered significant with GI complications including age greater than 70 years, long duration of cardiopulmonary bypass, blood transfusion, reoperation, ischemic heart disease, renal failure, and low cardiac index [10]. One of the pivotal studies in this area was conducted by Byhahn et al. [11]. This is a prospective study that sought to determine risk factors for subsequent GI complications after cardiosurgical procedures. The authors identified low cardiac output syndrome, loss of sinus rhythm and onset of atrial fibrillation, and vasopressor support as additional risk factors leading to GI complications.

One of the key potential risk factors in the development of GI complications is the use of the cardiopulmonary bypass (CPB) machine. Off pump CABG has been promoted by many cardiothoracic surgeons as better than on pump CABG in terms of reduced neurological complications, decreased morbidity and mortality, and renal dysfunction [12]. The impact of CPB on the development of GI complications has been studied with varied results $[13,14]$. Sanisoglu et al. showed that the incidence rates of GI complications were similar in the on- and off-pump coronary artery bypass groups, the type of GI complications, however, was different. CPB did not emerge as a risk factor for GI complications, but prolonged CPB (longer than 98 minutes) resulted in a high incidence of such complications [14]. Further research in this area will be required in order to clarify these results.

Although rare, the impact of abdominal surgery resulting from GI complications is significant. The patients who had abdominal surgery and underwent CABG were more likely to develop multiple complications. As a result, these patients had a higher rate of mortality, longer LOS, and higher hospital costs. Taken together, these results indicate that patients with GI complications should be identified promptly and aggressively treating these patients is of paramount importance.

\section{References}

1. McSweeney ME, Garwood S, Levin J, Marino MR, Wang SX, et al. (2004) Adverse gastrointestinal complications after cardiopulmonary bypass: can outcome be predicted from preoperative risk factors? Anesth Analg 98: 16101617.

2. Mercado PD, Farid H, O'Connell TX, Sintek CF, Pfeffer T, et al. (1994) Gastrointestinal complications associated with cardiopulmonary bypass procedures. Am Surg 60: 789-792.

3. Ott MJ, Buchman TG, Baumgartner WA (1995) Postoperative abdominal complications in cardiopulmonary bypass patients: a case-controlled study. Ann Thorac Surg 59: 1210-1213.

4. Welling RE, Rath R, Albers JE, Glaser RS (1986) Gastrointestinal complications after cardiac surgery. Arch Surg 121: 1178-1180.

5. D'Ancona G, Baillot R, Poirier B, Dagenais F, de lbarra JI, et al. (2003) Determinants of gastrointestinal complications in cardiac surgery. Tex Heart Inst J 30: 280-285.

6. Yoshida K, Matsumoto M, Sugita T, Nishizawa J, Matsuyama K, et al. (2005) Gastrointestinal complications in patients undergoing coronary artery bypass grafting. Ann Thorac Cardiovasc Surg 11: 25-28. 
Citation: Lemaire A, Batsides G, Ghaly A, Solina A, Dombrovsky V, et al. (2014) The Impact of Gastrointestinal Complications on Patients who Undergo Coronary Artery Bypass Grafting. J Cardiovasc Dis Diagn 2: 153. doi:10.4172/2329-9517.1000153

Page 3 of 3

7. Rodriguez F, Nguyen TC, Galanko JA, Morton J (2007) Gastrointestinal complications after coronary artery bypass grafting: a national study of morbidity and mortality predictors. J Am Coll Surg 205: 741-747.

8. Berkowitz D (1963) Fatal Gastrointestinal Hemorrhage; Diagnostic Implications from a Study of 200 Cases. Am J Gastroenterol 40: 372-377.

9. Rosemurgy AS, McAllister E, Karl RC (1988) The acute surgical abdomen after cardiac surgery involving extracorporeal circulation. Ann Surg 207: 323-326.

10. Aouifi A, Piriou V, Bastien O, Joseph P, Blanc P, et al. (1999) [Severe digestive complications after heart surgery using extracorporeal circulation]. Can $\mathrm{J}$ Anaesth 46: 114-121.

11. Byhahn C, Strouhal U, Martens S, Mierdl S, Kessler P, et al. (2001) Incidence of gastrointestinal complications in cardiopulmonary bypass patients. World $J$ Surg 25: 1140-1144

12. Puskas JD, Edwards FH, Pappas PA, O’Brien S, Peterson ED, et al. (2007) Offpump techniques benefit men and women and narrow the disparity in mortality after coronary bypass grafting. Ann Thorac Surg 84: 1447-1454.

13. Mack MJ, Pfister A, Bachand D, Emery R, Magee MJ, et al. (2004) Comparison of coronary bypass surgery with and without cardiopulmonary bypass in patients with multivessel disease. J Thorac Cardiovasc Surg 127: 167-173.

14. Sanisoglu I, Guden M, Bayramoglu Z, Sagbas E, Dibekoglu C, et al. (2004) Does off-pump CABG reduce gastrointestinal complications? Ann Thorac Surg 77: 619-625. 